\title{
Multiple payers, commonality and free-riding in health care: Medicare and private payers
}

\author{
Jacob Glazer ${ }^{\mathrm{a}}$, Thomas G. McGuire ${ }^{\mathrm{b}, *}$ \\ a Tel Aviv University, Tel Aviv, Israel \\ ${ }^{\mathrm{b}}$ Harvard University, 180 Longwood Ave, Boston, MA 02115, USA
}

Received 1 November 2001; accepted 1 June 2002

\begin{abstract}
Managed health care plans and providers in the US and elsewhere sell their services to multiple payers. For example, the three largest groups of purchasers from health plans in the US are employers, Medicaid plans, and Medicare, with the first two accounting for over $90 \%$ of the total enrollees. In the case of hospitals, Medicare is the largest buyer, but it alone only accounts for $40 \%$ of the total payments. While payers have different objectives and use different contracting practices, the plans and providers set some elements of the quality in common for all payers. In this paper, we study the interactions between a public payer, modeled on Medicare, which sets a price and takes any willing provider, a private payer, which limits providers and pays a price on the basis of quality, and a provider/plan, in the presence of shared elements of quality. The provider compromises in response to divergent incentives from payers. The private sector dilutes Medicare payment initiatives, and may, under some circumstances, repair Medicare payment policy mistakes. If Medicare behaves strategically in the presence of private payers, it can free-ride on the private payer and set its prices too low. Our paper has many testable implications, including a new hypothesis for why Medicare has failed to gain acceptance of health plans in the US.
\end{abstract}

(C) 2002 Elsevier Science B.V. All rights reserved.

JEL classification: I11; I18

Keywords: Medicare; Health insurance; Quality

\section{Introduction}

In the US and elsewhere, health plans contract with many payers. When enrollees from different payers join an HMO, they share features of the quality of the plan. Health care providers also accept patients from many plans and payers. Patients admitted to the medical

\footnotetext{
* Corresponding author.

E-mail address: mcguire@ @cp.med.harvard.edu (T.G. McGuire).
} 
unit of a hospital, from Medicare or from a private employer, receive some elements of quality in common. When a plan or provider makes a decision about shared quality or other characteristics in response to the aggregate incentives it faces, buyers are in effect "compromising" among themselves. ${ }^{1}$

In this paper we analyze health plan and provider behavior when selling to Medicare and private buyers. A key feature of our analysis is Medicare's distinctive buying practices in both the market for plans and for providers. In contrast to private buyers, Medicare sets prices administratively and accepts supply from any willing qualified provider. As we will discuss below, this is the opposite of the practice of private buyers. Analysis of Medicare's interaction with the private sector over a shared quality leads to new perspectives on the contracting problems of both parties. ${ }^{2}$ The force of the insights depends critically on the degree of shared quality, which is likely to differ in the cases of physicians, hospitals and plans. Nevertheless, at a general level, the same theory applies.

Medicare's contracting practices with health plans are the subject of many policy papers, most addressing the issue of how Medicare should risk adjust the prices paid to plans in order to enlist more plan participation and to avoid other problems related to adverse selection (Newhouse, 2002; van de Ven and Ellis, 2000). While the analysis presented here has implications for risk adjustment and other components of Medicare payment policy, our starting point is different than previous research. We are aware of no paper on Medicare payment policy that recognizes that Medicare accounts for just $7 \%$ of the enrollment and $14 \%$ of the revenue at health plans. ${ }^{3}$ Rather than ignoring this fact, we regard it as central to understanding what is happening to Medicare, and what should be done about it.

The impact of multiple payers has been considered most frequently in the context of hospital payment and "cost shifting." In a recent paper, Bernard (2000) finds that Medicare payment levels are inversely related to hospital prices to managed care plans. Interdependence among payers can go beyond price effects. The level of resource use of a joint cost such as a piece of capital equipment in a hospital will be affected by the set of payers supporting the investment (Ma and McGuire, 1993). Nursing homes are required by law to provide a common quality to all residents regardless of their payer source (Grabowski,

\footnotetext{
${ }^{1}$ Goldstein and Pauly (1976) regarded the common coverage features of health insurance as having public good elements. The compromise in their case was among members of the insurance pool.

2 Analysis of Medicare payment and contracting is altered dramatically by recognition that Medicare is only one of the payers buying from these providers. For example, as Medicare reset its procedure-level prices to physicians during the early 1990s, there was a concern that physicians would respond to an imposed price fall by inducing demand to maintain a "target income." In this context, ignoring other payers implied that physicians sought a "Medicare target income" and would recoup any income losses by increasing Medicare volume, an assumption made by Medicare when it figured the overall level of payment based on a uniform $50 \%$ volume response. When another payer is present, the physician will want to recoup some of the income loss from that payer as well. Furthermore, if Medicare's price is reduced, the other payer becomes a relatively more favorable place to induce demand. Inducement in Medicare might even fall. Over and above the point about multiple payers, the literal target-income theory is implausible and not supported by research. The target-income theory can be understood as an extreme form of income effects (McGuire and Pauly, 1991). For a test confirming the predictions of income effects of Medicare price changes on other papers, see Yip (1998).

3 The numbers are derived from information from HCFA for Medicare, Holahan et al. (1999) for Medicaid and Interstudy (1999) for the private sector. See Keenan et al. (2001). We are aware of no paper analyzing Medicare's payment policy to health plans that incorporates the presence of other payers.
} 
2001). This observation has been the basis of the theoretical and empirical research on the nursing home industry (Scanlon, 1980; Gertler, 1989). Beaulieu (2000) models two payers, buying from overlapping sets of providers. Each provider can set only one quality, but she pursues the implication of this shared quality in a different direction from our paper. In her model, the payers compete (for enrollees), introducing a strategic interaction not addressed here. In a recent paper, Glied and Zivin (2002) find empirical support for the idea of commonality in "intensity" of visits at the physician level. One finding is that the time doctors spend with patients depend on the aggregate incentives at the practice level.

The medical policy literature has recently called attention to how the mix of incentives facing a provider interferes with policies to induce good quality from providers. The Institute of Medicine in its recently released Crossing the Quality Chasm, concludes that, ${ }^{4}$

It is important to note . . that most providers receive payment from a variety of payers that may rely on different methods. Therefore, any given provider faces a mix of incentives and rewards, rather than a consistent set of expectations. This mix has a significant influence on how payment methods can inhibit quality improvement. (p. 189)

Our paper relates to the literature in industrial organization dealing with "common agency" and vertical contracting. (See Bernheim and Whinston, 1986; Katz, 1989.) The results from this literature, however, do not have direct application to the problem addressed here. In our model one payer pays directly on quality whereas the other sets prices in advance. This special feature, driving many of our results, makes our analysis distinct.

The basic model in this paper (contained in Sections 3 and 4) is a simple one: a health plan or provider offers its services to both the public sector (Medicare) and the private sector (employers). When we say "provider," we will mean it to apply to a health plan as well as a hospital or other providers. Some service characteristics (quality) determined by the provider are shared by both payers. Because of different objectives and contracting practices, the quality would be different had the provider contracted with only the private or the public payer. Thus, when contracting with both, the provider's profit-maximizing quality is a compromise between the two payers (Proposition 2). Compromise has two immediate implications: first, in some circumstances, compromise implies repair, in the sense that the provider's decision about shared quality improves the efficiency of the quality choice for one or both of the payers. Second, efforts by a payer to affect quality will be diluted by the presence of the other payer. Other implications also follow from a provider's compromise. If the public payer behaves strategically, it will free-ride on the private payer by offering a contract to the provider with a low price, and relying on the private sector to repair the quality damage such a contract, standing alone, would inflict (Proposition 2). Finally, the provider anticipates compromising the private payer's interests if it serves Medicare beneficiaries. To be willing to participate with Medicare, the provider must be compensated by a Medicare price high enough to cover costs plus the profits lost from the private sector (Proposition 3). Before presenting the analysis, Section 2 summarizes the contracting practices of Medicare and the private sector in buying from plans and providers, highlighting the contrasts between the two approaches.

\footnotetext{
${ }^{4}$ We are grateful to a referee for pointing out this reference. For a similar point about quality improvement, see McNeil (2001).
} 


\section{Buying from plans and providers}

Health plans and providers do not generally specialize in the services of one payer. Virtually all hospitals, for example, see Medicare patients, private patients, and Medicaid patients, as well as patients from other payers. Health plans accept enrollees from multiple payers, at least in the sense of more than one employer. Furthermore, virtually every plan that accepts Medicare enrollees also accepts private enrollees. ${ }^{5}$ Not all doctors take patients from all sources (declining to participants in Medicaid is common) but virtually all doctors also serve more than one payer. All plans and providers must contend with the incentives introduced by multiple payers.

\subsection{Medicare}

In this description of Medicare's buying practices, we focus on two aspects of Medicare's contracting. First, Medicare employs nationwide rules about rates of payment to qualified plans and providers. In essence, Medicare sets prices. In the case of health plans, Medicare applies a formula to determine the price that it will pay for a beneficiary joining a plan. The formula is based on adjusted average costs in the fee-for-service sector in the beneficiary's county in past years, the national average of those costs, and risk adjuster variables. The person-specific risk adjusters are age, gender, and Medicaid status, and since 2000, diagnoses from hospital claims from the previous year (Pope et al., 2000). The premium formula is determined in advance and made known to plans, including the rules by which the premium is adjusted over time. ${ }^{6}$

Medicare applies a formula to set prices for all hospitals and physicians. In the case of hospitals the formula is based on Diagnoses-Related Groups (DRGs) and in the case of physicians, on the Resource-Based Relative Value Scale (RBRVS). Hospital prices are set on a more aggregated level—at the discharge rather than the procedure—resulting in many fewer hospital prices than physician prices. Doctors, within very strict limits, may charge some extra price to beneficiaries, hospitals may not. Nonetheless, in broad terms Medicare's DRG-based and RBRVS-based price systems are similar: both are national systems in which the price paid depends on characteristics of the provider (teaching/non-teaching hospital, physician specialty), characteristics of the patients (age, new/established patients), and activity conducted (surgery yes or no, procedure). Providers must take Medicare's price formula as given.

The second key feature of Medicare contracting is that Medicare accepts any qualified plan or provider that wishes to supply at those prices. Health plans decide to contract with Medicare (for a period of a year) based on the prices they would be paid for beneficiaries and on the costs they anticipate, including any extra administrative costs associated with

\footnotetext{
${ }^{5}$ Recent regulatory changes allow Medicare-only plans, but so far these are trivial in Medicare (MedPAC, 2002).

${ }^{6}$ Health plans must provide the same basic services available to Medicare beneficiaries in the FFS sector. In addition, Medicare employs a regulatory mechanism to estimate costs of these services at a plan. If the cost is estimated to be enough less than the payment, the plan must provide extra services (e.g. eye glasses) to beneficiaries. See Encinosa and Sappington (1999) for a discussion and analysis of the regulatory mechanism. Medicare also regulates in what circumstances an extra premium can be charged to beneficiaries, and how much this premium can be.
} 
Medicare participation. Health plans are free to accept beneficiaries from some counties and not others. Once a plan decides to accept enrollees from a county, it must accept all enrollees who apply and the volume of business is determined by demand response.

A similar process describes hospitals and physicians. US hospitals have the option to accept Medicare patients and be paid by DRGs. Virtually all hospitals exercise this option. Once a hospital participates with Medicare, it must accept all Medicare admissions. Physicians also decide if they wish to participate with Medicare, though they have an additional option in comparison to hospitals. Physicians can participate at the practice level or on a service-by-service basis. Medicare may not refuse to pay any qualified plan, hospital or physician that elects to supply services to Medicare.

\subsection{Private buyers}

The contracting practices of private employers are nearly the opposite of Medicare's. Employers do not set prices paid to providers. They either accept prices set by providers, or negotiate with providers about prices. Employers do not accept any qualified provider, but choose the set of providers to contract with.

Employers buy directly from health plans. Prices paid by an employer to a plan reflect bargaining, and the different risk distributions plans expect from different employers. Table 1 shows prices paid by several employers to several health plans in the Boston area in 2001. Two things are evident: first, employers pay different amounts to different plans for the same person. Harvard, for example, pays different prices to plans for enrolling a single employee. Second, plans charge different prices to different employers for membership in the same plan. Harvard Pilgrim Health Care (a PPO-type plan) gets US\$ 237 for a single Harvard enrollee, and US\$ 295 for a single Boston College enrollee. While one can readily come up with various reasons why prices should differ in these two dimensions, we simply make the point here that a price paid is negotiated between the plan and the employers.

Private employers do not contract with every plan in a market. More than half of private employees have no choice of plans (Marquis and Long, 1999). Most state governments act like private employers when buying health insurance for employees, though a few states, such as California, are more "open" with respect to plan contracting. The federal

Table 1

Prices paid (US\$) to selected health plans for a single employee four employers, Boston area, 2001

\begin{tabular}{lllll}
\hline Plan & \multicolumn{2}{l}{ Employer } & & \\
\cline { 2 - 5 } & $\begin{array}{l}\text { Boston } \\
\text { University }\end{array}$ & GIC & $\begin{array}{l}\text { Harvard } \\
\text { University }\end{array}$ & $\begin{array}{l}\text { Boston } \\
\text { College }\end{array}$ \\
\hline Fallon Community Health Plan (HMO) & & 184 & 206 & 265 \\
Harvard Pilgrim Health Care (HMO) & & 240 & 226 & 252 \\
Tufts Associated Health Plan (HMO) & 231 & 230 & 237 & 295 \\
BMC preferred (HMO) & 150 & & 237 \\
Harvard Pilgrim Health Care (PPO) & & & & 265 \\
\hline
\end{tabular}

Notes: GIC is Group Insurance Commission buying on behalf of public employees. Not all plans offered by these employers are shown. 
Table 2

Contracting practices of Medicare and private buyers in the market for health plans and providers

\begin{tabular}{lll}
\hline & Medicare & Private \\
\hline $\begin{array}{ll}\text { Prices } \\
\begin{array}{l}\text { Choice of plans } \\
\text { or providers }\end{array}\end{array}$ & $\begin{array}{l}\text { Pricing formula set by Medicare } \\
\text { Takes any willing }\end{array}$ & $\begin{array}{l}\text { Negotiated or set by plan or provider } \\
\text { Chooses one or a few plans or a } \\
\text { subset of providers }\end{array}$ \\
\hline
\end{tabular}

government, as an employer, is a hybrid. It is close to "open" with respect to plans seeking contracts, but negotiates prices (based on a formula) with potential contractors (Merck, 1999). The Federal Employees Health Benefit Plan (FEHBP) has the authority to deny a contract to a potential health plan, but appears to rarely exercise this authority.

We regard private employers' authority to not contract with a plan or provider as the fundamental difference between Medicare and private buyers. The difference may be at root of explanations for why Medicare and private buyers contract in such different ways. The employer's decision about which provider or providers to offer to employees is made simultaneously with any negotiation about price. ${ }^{7}$ Employers decide to offer a provider based on the price they receive or can negotiate, and based on the characteristics of the provider.

Employers and other private buyers do not usually contract directly with hospitals and physicians, relying on the health plan to establish these relationships. The prices paid by a plan to providers is a matter of negotiation. It is most common for hospitals to be paid based on a per diem, and physicians to be paid by procedure, but there is a wide range of contracting practices, with the level of prices and per diems as well as other contract features being part of negotiations.

Health plans contract with some of the physicians and hospitals within their market area, creating a "network" of providers in the plan. A few old-style indemnity plans offer enrollees free choice of providers, and many so-called "point-of-service" plans allow enrollees to use out-of-network providers and receive lower insurance benefits. Nonetheless, a plan contracts with the providers it chooses.

Table 2 summarizes the contracting practices of Medicare and private employers, highlighting the differences between these two purchasers. Medicare and employers' practices are behind our stylized "public" and "private" purchaser analyzed below.

\section{Multiple payers and provider choice of service quality}

In this section we consider the implications of Medicare and private employers-with their distinct contracting approaches_-sharing the same quality of services set by a provider.

\footnotetext{
7 There are some other differences in the way Medicare and private employers contract with health plans. Health plans do not set the premium charged to private employees. Premium charges to employees are set by the employer (and the money collected offsets the employers' premium payment to the plan). Finally, private employers virtually never use a formal risk adjustment formula to pay plans. Less than $1 \%$ of employees are paid for using formal adjustment (Keenan et al., 2001). For consideration of why public and private buyers make such different use of formal risk adjustment, see the papers in Inquiry, Fall 2001. Prices are normally negotiated for "individual" or "family" plans, or tiers counting ranges of persons in a family group.
} 


\subsection{Quality and shared quality}

Quality and shared quality of a health plan or provider play an important role in our analysis. Quality refers to any characteristic of a plan or provider observed and valued by consumers. An element of quality is shared between buyers if the decision a provider makes about quality to one buyer affects the decision the provider makes about quality to the other buyer. We will use the term "commonality" to refer to shared quality. Cost considerations can give rise to commonality. Economies of scale or scope can mean that a decision made for one buyer influences that for another. Consider the production of hospital care. In principle it would be possible to make personnel decisions separately for Medicare and private buyers, perhaps even establishing separate wards for patients from different payers. In practice, however, this is not done. The same nursing and house staff distributes itself across the demands from all patients. Equipment in the hospital, availability of surgical and lab facilities, food, laundry, housekeeping and many other functions are essentially common to all patients using the hospital. Commonality may also be the result of strategic considerations. Payers or providers may find it desirable if some elements of quality are shared, and they may take various actions to induce and preserve commonality. In Section 4.2 we pursue this point in the context of public and private payers contracting with health plans.

Our argument is not that all elements of quality are common or even the ones that are shared are shared equally; it is only that a substantial amount of commonality exists. Nursing staff in a hospital does not have to be equally available to all patients for some commonality to exist; it is sufficient that the general level and quality of a staff has a common effect for all patients in the hospital. Furthermore, for our analysis to go through it is sufficient that patients perceive some elements of quality in common.

Commonality extends to other providers, such as physicians. Physicians can and do differentiate their services according to payer, in scheduling availability, and in time spent with patients, for example. Nonetheless, there are important elements of quality that are shared, including the clinical skills of the physician in question, the quality and size of the physician's support staff, on-site facilities, and other factors.

In the case of health plans there is explicit product differentiation in the services available to Medicare and private buyers. Indeed, Medicare requires beneficiaries to be enrolled in a special Medicare "product" not available to other populations served in the health plan. In a staff model HMO, however, we expect the providers would be nearly identical for Medicare and other payers and the commonality to be high. The degree of commonality in the networks set up for the Medicare and private products for PPO-type plans is an empirical question. For one plan in the Boston area, the hospitals in the Medicare network are a proper subset of the hospitals in the employer-product network, building in some commonality in the networks. All hospitals in the smaller Medicare network must therefore be in the larger commercial network. Economies in contracting would imply an overlap in the providers chosen for the two networks.

\subsection{The public payer: Medicare}

To simplify our presentation we assume in this section that all Medicare members are identical in their demand for health care. We also assume here that the provider supplies 
only one health service. In this section we thus ignore asymmetric information and adverse selection. ${ }^{8}$ These issues will be discussed in Section 4 .

To study the effects of commonality on providers' decisions, we analyze the behavior of a representative provider. ${ }^{9}$ Let $m_{\mathrm{M}}$ denote the dollar amount the provider will spend on a Medicare beneficiary if he chooses the provider. This is known by the potential enrollee. The dollar value of the benefits the individual expects from being served by the provider, $u_{\mathrm{M}}\left(m_{\mathrm{M}}\right)$ is composed of two parts, a valuation of the service the individual gets from the provider and a component of valuation that is independent of the service. We assume that

$$
u_{\mathrm{M}}\left(m_{\mathrm{M}}\right)=v_{\mathrm{M}}\left(m_{\mathrm{M}}\right)+\mu
$$

where $v_{\mathrm{M}}(\cdot)$ is the service-related component of the valuation, with $v_{\mathrm{M}}^{\prime}>0, v_{\mathrm{M}}^{\prime \prime}<0$. The non-service component $\mu$ is an individual-specific factor (e.g. distance or convenience) affecting the individual's valuation, known to the person. The provider does not know the true value of each individual $\mu$, but knows it is drawn from a distribution $\Phi(\mu)$.

The price the provider receives from Medicare has been predetermined and equals $r_{\mathrm{M}}$. We assume this is the only revenue the provider receives from the public payer; in particular, the provider charges no additional fee to Medicare beneficiaries.

The situation we have in mind is one where Medicare first announces the price per service, $r_{\mathrm{M}}$. Secondly, the provider decides whether to supply services to Medicare's patients and if so the level of service, $m_{\mathrm{M}}$. Thirdly, after observing the provider's level of service, the patient decides whether to use its services. In this section we study the last stages of the game. Namely, we take Medicare's price $r_{M}$ as given and study the provider's decision about $m_{\mathrm{M}}$ and the patient's decision whether or not to use its services. This analysis is carried out in reverse looking first at the patient's decision, given $m_{\mathrm{M}}$.

Given $m_{\mathrm{M}}$, the provider will be chosen by the individual if $u_{\mathrm{M}}\left(m_{\mathrm{M}}\right)>\bar{u}$, where $\bar{u}$ is the valuation the individual places on the next-preferred provider. Competition among providers will probably affect $\bar{u}$. The more (potential) providers there are in the Medicare market, the higher will be $\bar{u}$ for each particular provider. Given $m_{\mathrm{M}}$ and $\bar{u}$, the individual chooses the provider if

$$
\mu>\bar{u}-v_{\mathrm{M}}\left(m_{\mathrm{M}}\right)
$$

Therefore, for a given $m_{\mathrm{M}}$ the probability that the individual chooses the provider, from the point of view of the provider, is

$$
n_{\mathrm{M}}\left(m_{\mathrm{M}}\right)=1-\Phi\left(\bar{u}-v_{\mathrm{M}}\left(m_{\mathrm{M}}\right)\right)
$$

Turn now to the decision of the provider. Providers ration the amount of health care a patient receives. "Commonality" in the provision of some service means that the provider uses the same or similar mechanisms to ration the service $m$ for the public and the private

\footnotetext{
${ }^{8}$ A generalization of the Medicare model presented here to the case of multiple types of consumers and many services, to address issues of asymmetric information and adverse selection, can be found in Frank et al. (2000) and Glazer and McGuire (2002). These papers, however, do not study the issues of commonality and the interaction with private payers.

${ }^{9}$ Even though we focus on a representative provider, we do not completely abstract from competition among providers. The effects of such competition will be discussed as we go along.
} 
patients. To represent commonality in our framework we adopt the concept of shadow prices. (See Keeler et al., 1998 and Frank et al., 2000.) Let $q$ be a shadow price the provider sets determining access to care. A Medicare patient will receive an amount of services $m_{\mathrm{M}}$ determined by

$$
v_{\mathrm{M}}^{\prime}\left(m_{\mathrm{M}}\right)=q
$$

The shadow price is a device to capture the myriad of strategies a provider uses to ration care, other than by demand-side cost sharing (literal prices). Shadow prices can reflect, for example, hospital decisions about capacity in various service areas, or plan decisions about the number of specialists in a physician network or the number of staff hired in a provider department. They could reflect the makeup of networks or payment to providers, including supply-side cost sharing or the stringency of utilization review. When we turn to provider behavior, we will characterize the choice of $q$ to maximize profits. For further discussion of the shadow price methodologyin the context of a health plan, see Frank et al. (2000).

Let $m_{\mathrm{M}}(q)$ denote the amount of the provider's spending on a Medicare enrollee determined by (3.4). Since we measure quantity in terms of spending, we regard the marginal cost of one dollar to be 1 . Note that since $v_{\mathrm{M}}^{\prime}$ can be interpreted as the marginal benefit of spending, and assuming that the individual's benefit coincides with the social one, the socially efficient shadow price is when $q=1$.

Define

$$
n_{\mathrm{M}}(q) \equiv n_{\mathrm{M}}\left(m_{\mathrm{M}}(q)\right)
$$

Using (3.3)-(3.5) and our assumptions about $v_{\mathrm{M}}$, it is easy to see that $n_{\mathrm{M}}^{\prime}(q)<0$, the higher is the shadow price, the lower is the probability that a Medicare member will choose the provider. Let $N_{\mathrm{M}}$ be the total number of Medicare beneficiaries who may choose a provider. Then, the number of Medicare's beneficiaries choosing the provider (later referred to as Medicare's demand), is $N_{\mathrm{M}} n_{\mathrm{M}}(q)$. Profit from Medicare can be written as

$$
\pi_{\mathrm{M}}(q)=N_{\mathrm{M}} n_{\mathrm{M}}(q)\left[r_{\mathrm{M}}-m_{\mathrm{M}}(q)\right]
$$

The crucial assumption we make is that quality, $q$, is not verifiable by Medicare and, hence, cannot be part of the contract between Medicare and the provider. The only way Medicare can affect $q$ is via the price $r_{\mathrm{M}}$. How Medicare can use this tool to affect quality will be analyzed in Section 4.

\subsection{The private payer}

Before we say how the provider chooses the level of rationing, $q$, to maximize profit, we must describe the provider's revenue and cost for the private payer. We begin with the discussion by considering one private payer. Cost per person is determined by the same process as in Medicare. The dollar value to the private individual if the provider spends $m_{\mathrm{P}}$ serving this individual is $v_{\mathrm{P}}\left(m_{\mathrm{P}}\right)$. As in the case of Medicare, we assume all individuals in the private sector are identical and have the same $v_{\mathrm{P}}$ function. Since quality of service is going to be common to both the public and the private payer, we assume here too that 
quality is modeled by the shadow price $q$, and that for a given $q$, the level of spending on a private individual is determined by

$$
v_{\mathrm{P}}^{\prime}\left(m_{\mathrm{P}}\right)=q
$$

This allows us to define costs per person as a function of $q, m_{\mathrm{P}}(q)$.

Total costs depend on costs per person and enrollment. The enrollment process works differently in the private market. All private payers restrict choice. To represent this difference we assume the private payer restricts the choice of its $N_{\mathrm{P}}$ private employees to this one provider and the probability of each employee using the provider's service is normalized to one. This restriction is meant to represent, in the case of health plans, the employer's decision to limit employees' choice to one or a few plans, and in the case of hospitals and physicians, the private plan's creation of a network of preferred providers. Thus, total costs can be written as $N_{\mathrm{P}} m_{\mathrm{P}}(q)$.

Perhaps the most difficult problem faced by payers for health care services is that the quality of these services is not verifiable and hence, cannot enter directly into the contract between the payer and the provider (Ma, 1994; Chalkley and Malcomson, 2000; Newhouse, 2002). In the absence of verifiability, payers must rely on indirect means to induce their desired quality. However, the lack of verifiability is less of a problem for private payers, so long as the quality is observable. The private payer can simply choose a provider based on observable characteristics. If a certain provider is known to be of low quality, the private payer can simply chose not to use its services, or, alternatively, to pay it a low price, without having to justify its decision. Since the price can be thought of as cost plus a markup, the upshot of this argument is that any markup over costs will also depend on $q$.

Therefore, the price for each enrollee the provider charges the private payer, $r_{\mathrm{P}}$, is a function of $q$ and can be represented as follows:

$$
r_{\mathrm{P}}(q)=H(q)+m_{\mathrm{P}}(q)
$$

where $H(q)$ refers to the "height" of the markup of price over cost. As in a typical model of pricing, a markup function will depend on many factors, such as demand and market structure. Since $q$ is a product quality measure, the derivative $H^{\prime}(q)$ cannot be signed. A strength of our model is that the analysis can proceed with this very general description of the markup.

Consider some special cases of $H(q)$ coming from different market structures. In the case of a very competitive market, $H(q)$ will be close to zero for all values of $q$. If a provider is a monopolist, $H(q)$ may be substantially above zero, at least for some values of $q$. In intermediate cases of imperfect competition, $H(q)$ will be positive at least in some ranges.

$H(q)$ will also depend on a payer's demand. One interesting case is where $H(q)=$ $\alpha\left(v_{\mathrm{P}}(q)-m_{\mathrm{P}}(q)\right)$. In this case, the markup divides the surplus of value to employees over cost between the employer and the provider. The division according to $\alpha$ would be determined by market forces. In this special case, the $q$ that maximizes profit is the same value that maximizes the employee's surplus. This case corresponds to socially efficient private purchasing with the employer seeking to maximize the value of a total compensation package to workers. While competition in labor markets pushes employers to buy efficiently on behalf of workers, other forces can interfere. The tax subsidy to non-wage compensation encourages "overinsurance," which in a managed care context corresponds to a too loose 
rationing regime (too low $q$ ). On the other hand, short-term contracts and adverse selection concerns may induce employers to choose plans that ration too tightly (too high a $q$ ). In any of these cases, the general description of $H(q)$ can be used.

Although our discussion deals with one private payer, the $H(q)$ representation can handle the existence of many private payers. Suppose there were two payers with different demands and possibly different costs $\left(m_{\mathrm{P}}(q)\right)$. Assuming the provider is willing to contract with both payers, the markup function $H(q)$ can simply be regarded as the average of the two separate $H(q)$ functions weighted by the number of employees in each private payer. (Each of the two private payers will be paying a distinct price determined by their own $H(q)$ function.) This averaging process raises some interesting issues. ${ }^{10}$ One particular concern is that because of commonality, each private payer might seek to pay as little as possible towards shared quality, initiating a "race to the bottom" in terms of quality in the market for health plans. This, however, will not happen in our model. Although quality is shared it is not a pure public good in the sense that average cost per person equals marginal cost (with appropriate allowance for any "risk adjustment"). Doubling the number of patients seen in a provider network approximately doubles the costs of care. Nursing time is the biggest single expense of hospital care, and the demand for time will go up directly in proportion to the number of patients. Providers can refuse to contract with any payer not covering its costs, frustrating any attempt to "free-ride" among private buyers.

Using (3.8) it is easy to see that provider profit in the private sector will be:

$$
\pi_{\mathrm{P}}(q)=N_{\mathrm{P}}\left[r_{\mathrm{P}}(q)-m_{\mathrm{P}}(q)\right]=N_{\mathrm{P}} H(q)
$$

We simply assume that (3.9) reaches a maximum at some $q_{\mathrm{P}}^{e}>0$ (i.e. $H^{\prime}\left(q_{\mathrm{P}}^{e}\right)=0$ ) and $H^{\prime}>0$ for $q<q_{\mathrm{P}}^{e}$ and $H^{\prime}<0$ for $q>q_{\mathrm{P}}^{e}$.

\subsection{Provider profit maximization}

The profit maximizing provider decides about the stringency of rationing in light of the profit consequences in the public and private markets considered together. The assumption that the provider chooses the same level of shadow price $q$ for the private and public sector aims to capture our "commonality" idea. Of course providers' decisions are not one-dimensional and some of the decisions they make are (more) common and some are not (or less). Furthermore, whether quality decisions are common is often endogenous to the provider and may be part of its strategy, depending on, among other thing, whether there are economies or diseconomies of scope. However, the purpose of our paper is to study the implications for Medicare's behavior, when such common decisions exist. For this purpose we make the simplifying assumption that quality $(q)$ must be the same for the private and public sector. ${ }^{11}$ Combining the expressions for profit for both public and private payers, we have

$$
\pi(q)=\pi_{\mathrm{M}}(q)+\pi_{\mathrm{P}}(q)=N_{\mathrm{M}} n_{\mathrm{M}}(q)\left[r_{\mathrm{M}}-m_{\mathrm{M}}(q)\right]+N_{\mathrm{P}} H(q)
$$

\footnotetext{
10 The equilibrium distribution of payers among plans might be pursued along the lines of the literature on "clubs."

11 A more general model would assume that the $q$ 's could be different for the public and private payer but this differentiation is costly to the plan.
} 
The profit maximizing $q$ solves the following first-order condition:

$$
N_{\mathrm{M}} n_{\mathrm{M}}^{\prime}(q)\left[r_{\mathrm{M}}-m_{\mathrm{M}}(q)\right]-m_{\mathrm{M}}^{\prime}(q) N_{\mathrm{M}} n_{\mathrm{M}}(q)+N_{\mathrm{P}} H^{\prime}(q)=0
$$

We refer to the $q$ that solves (3.11) as $q^{e}$. Before discussing the profit maximizing condition above, we consider two extreme cases, one where $N_{\mathrm{M}}$ is (close to) zero and the other where $N_{\mathrm{P}}$ is (close to) zero.

When $N_{\mathrm{P}}=0$, we have a Medicare-only market and the provider will choose $q$ according to $(3.12)$

$$
\frac{r_{\mathrm{M}}-m_{\mathrm{M}}(q)}{m_{\mathrm{M}}(q)}=\frac{\epsilon_{m_{\mathrm{M}}}}{\epsilon_{n}}
$$

where $\epsilon_{n}=n_{\mathrm{M}}^{\prime} q / n_{\mathrm{M}}$ and $\epsilon_{m_{\mathrm{M}}}=m_{\mathrm{M}}^{\prime} q / m_{\mathrm{M}}$ are elasticities characterizing the response of Medicare individuals' probability of using the service and costs of service to changes in quality of services respectively and $\epsilon_{n}<0, \epsilon_{m_{\mathrm{M}}}<0$. One can see that more competition among providers would mean a higher $\bar{u}$ and, hence, a more elastic $\epsilon_{n}$. Eq. (3.12) is a markup, or more accurately, a markdown condition showing how much a provider will reduce costs per person, $m_{\mathrm{M}}(q)$, below revenue per person $r_{\mathrm{M}}$, dependent on cost and enrollment elasticities with respect to its stringency of rationing. ${ }^{12}$

Refer to the $q$ that solves (3.12) as $q_{\mathrm{M}}^{e}$, the profit-maximizing $q$ in the Medicare market. We can express $q_{\mathrm{M}}^{e}$ as a function of the Medicare price, $q_{\mathrm{M}}^{e}\left(r_{\mathrm{M}}\right)$. Assuming that, at $q_{\mathrm{M}}^{e}$, second-order conditions for a maximum are satisfied, one can see that $q_{\mathrm{M}}^{\prime e}\left(r_{\mathrm{M}}\right)<0$; that is, as the Medicare price rises, the profit-maximizing $q$ falls. Define $r_{\mathrm{M}}^{*}$ to be the socially efficient Medicare price in the sense of inducing the provider to ration efficiently; then, $r_{\mathrm{M}}^{*}$ is found as the solution to $q_{\mathrm{M}}^{e}\left(r_{\mathrm{M}}^{*}\right)=1$. When $r_{\mathrm{M}}<r_{\mathrm{M}}^{*}, q_{\mathrm{M}}^{e}>1$ and the provider rations too tightly; when $r_{\mathrm{M}}>r_{\mathrm{M}}^{*}, q_{\mathrm{M}}^{e}<1$ and the provider rations too loosely, relative to the socially efficient $q$. The inverse of the $q_{\mathrm{M}}^{e}\left(r_{\mathrm{M}}\right)$ function will be later denoted by $r_{\mathrm{M}}\left(q_{\mathrm{M}}^{e}\right)$.

If, on the other hand, the private payer's demand is much larger than the public sector's demand, i.e. $N_{\mathrm{M}}$ is close to zero, the first-order condition implies $q^{e}$ should be set close to $q_{\mathrm{P}}^{e}$ in order to maximize profit from the private payers.

\section{Analytical results}

This section summarizes our main analytical results.

\subsection{A provider compromises on quality}

Eq. (3.11) describes a provider's choice of shared quality. We know that when the private sector alone buys from a provider, $q^{e}=q_{\mathrm{P}}^{e}$. There is a special case in which this same quality would be supplied to Medicare. When $r_{\mathrm{M}}=r_{\mathrm{M}}\left(q_{\mathrm{P}}^{e}\right) \equiv r_{\mathrm{P}}^{e}$, a provider would supply the same quality to both payers. In the general case in which $r_{\mathrm{M}} \neq r_{\mathrm{P}}^{e}$, a provider compromises on the choice of quality in the sense that, when both payers are present, the choice of

\footnotetext{
${ }^{12}$ A condition like (3.12) is common in the literature on health payment. If we analyzed the decision about spending, $m$, instead of the shadow price $q$, (3.12) would take the form of a simple demand elasticity-driven markup. See Ma (1994).
} 


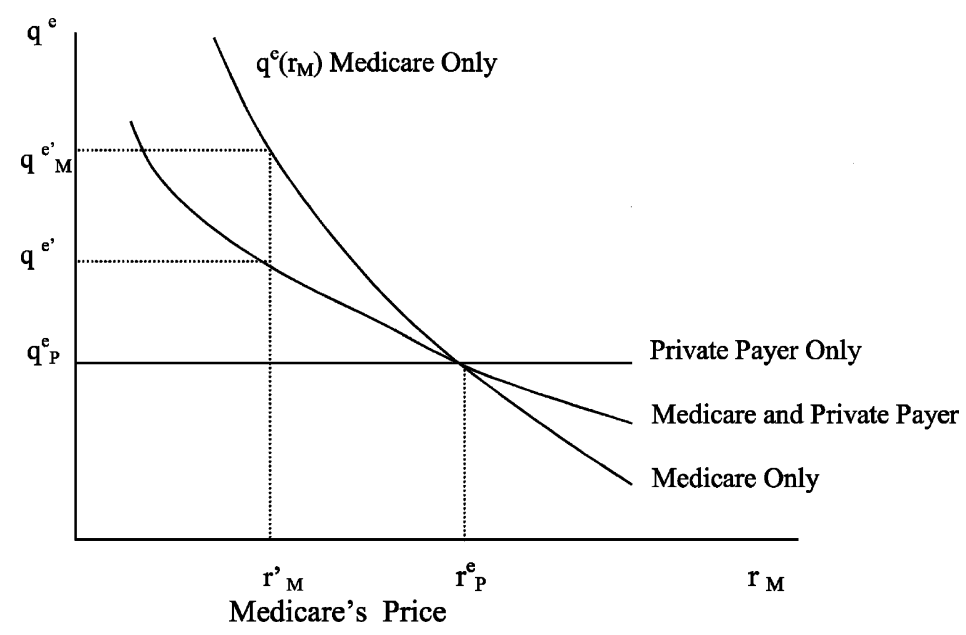

Fig. 1. The provider's compromise on quality.

quality falls between the quality the provider would have chosen for Medicare alone, given the Medicare price, and the quality the provider would have chosen for the private sector alone. We formalize this in Proposition 1, the proof of which follows directly from (3.11).

Proposition 2 (Compromise). When $N_{\mathrm{M}}>0$ and $N_{\mathrm{P}}>0$, if $r_{\mathrm{M}}>r_{\mathrm{P}}^{e}, q_{\mathrm{P}}^{e}>q^{e}>q_{\mathrm{M}}^{e}\left(r_{\mathrm{M}}\right)$ and if $r_{\mathrm{M}}<r_{\mathrm{P}}^{e}, q_{\mathrm{P}}^{e}<q^{e}<q_{\mathrm{M}}^{e}\left(r_{\mathrm{M}}\right)$.

Fig. 1 illustrates the compromise on quality with multiple payers. When Medicare is the only payer, there is a relatively steep trade-off between $r_{M}$ and $q^{e}$. (This is Eq. (3.11).) When Medicare is very small in the health plan market (in the extreme, there is the private payer alone), the line showing the effect of Medicare price on $q^{e}$ is flat at the $q_{\mathrm{P}}^{e}$; Medicare's price has no effect on the provider's choice of quality. When both payers are present, the "Medicare and Private Payer" line applies, and for any $r_{\mathrm{M}}$, such as $r_{\mathrm{M}}^{\prime}$, the provider chooses a quality, $q^{\prime e}$, in between the "Medicare-only" quality, $q_{\mathrm{M}}^{\prime e}$ and $q_{\mathrm{P}}^{e}$.

\subsubsection{When is compromise a repair?}

In this section we address a normative question: when does the compromise characterized in Proposition 2 constitute an improvement in the social efficiency of health plan rationing? The efficient level of rationing is where $q=1$, and generally, social welfare is a function of $q$ for each payer: $v\left(m_{\mathrm{M}}(q)\right)-m_{\mathrm{M}}(q)$ for the representative Medicare enrollee and $v\left(m_{\mathrm{P}}(q)\right)-m_{\mathrm{P}}(q)$ for the representative private enrollee. This section addresses more specifically the conditions under which $q^{e}$ is more efficient than $q_{\mathrm{M}}^{e}$ and $q_{\mathrm{P}}^{e}$, respectively for each payer.

Compromise constitutes repair for Medicare if

$$
v\left(m_{\mathrm{M}}\left(q^{e}\right)\right)-m_{\mathrm{M}}\left(q^{e}\right)>v\left(m_{\mathrm{M}}\left(q_{\mathrm{M}}^{e}\right)\right)-m_{\mathrm{M}}\left(q_{\mathrm{M}}^{e}\right)
$$

One case in which repair clearly takes places for Medicare is when private sector contracting is efficient, i.e. where $q_{\mathrm{P}}^{e}=1$. Then, $q_{\mathrm{M}}^{e}$ is "repaired" by compromise with the private sector. 
Efficiency in private contracting is not, however, necessary for Medicare repair. For example, suppose $q_{\mathrm{M}}^{e}>1$. Then, the range of private contracting for which repair would take place includes any $q_{\mathrm{P}}^{e}$ such that $q_{\mathrm{M}}^{e}>q_{\mathrm{P}}^{e}>1$, that is any $q_{\mathrm{P}}^{e}$ between the Medicare-only value and 1. The range also includes values in the "other side" of 1 , so long as the resulting compromise leads to a $q^{e}$ with higher surplus. The lower bound on this $q_{\mathrm{P}}^{e}$ could be characterized using the definition of repair and (3.11), but it is sufficient to note that the boundary (and range) depend on $H(q)$ and the shares of the two payers.

Compromise constitutes repair for the private sector when

$$
v\left(m_{\mathrm{P}}\left(q^{e}\right)\right)-m_{\mathrm{P}}\left(q^{e}\right)>v\left(m_{\mathrm{P}}\left(q_{\mathrm{P}}^{e}\right)\right)-m_{\mathrm{P}}\left(q_{\mathrm{P}}^{e}\right)
$$

As for Medicare repair, there is a range of values on both sides of 1 for which $q_{\mathrm{M}}^{e}$ repairs private contracting. One could also ask when compromise constitutes repair for both parties. If $q_{\mathrm{M}}^{e}$ and $q_{\mathrm{P}}^{e}$ are both on the "same side" of 1 , then compromise repairs only one payer. A necessary condition for compromise to repair both is when $q_{\mathrm{M}}^{e}$ and $q_{\mathrm{P}}^{e}$ are on opposite sides of 1 . One intriguing possibility is that a compromise between an overly generous private employer contract $\left(q_{\mathrm{P}}^{e}<1\right)$ induced by the tax subsidy and a low Medicare premium $\left(q_{\mathrm{M}}^{e}>1\right)$ improves the efficiency of the services to both payers.

The implications of repair extend to adverse selection and risk adjustment in the health plan context. If there is heterogeneity in health demands of Medicare beneficiaries, and if the low-demand individuals are more willing to switch to the HMO in comparison to the high-demand individuals (see, e.g. Feldman and Dowd, 2000, or Cutler and Zeckhauser, 2000), the plan will have an incentive to set $q$ "too high" to discourage the high-demand types and to effect a favorable risk selection. In the more general case of demand heterogeneity for many services, $q$ could be regarded as a vector of shadow prices the HMO sets to affect the mix of enrollees. The plan would set some elements of $q$ "too high" and some "too low," depending on the relationship among service demands and other factors (Frank et al., 2000). Both problems are essentially, however, a distortion of $q$ away from the efficient level. Repair implies that the degree of inefficiency associated with a Medicare premium (including one with risk adjustment) will be lower the larger is the private payer in the plan.

An analogous issue comes up in the hospital context. DRG prices are intended to risk adjust for the costs related to the severity of a patient's condition. A DRG payment too high or too low for a medical condition will distort care for that condition less because of the reparative private sector. Exactly the same argument goes through for physicians' services.

\subsubsection{Compromising dilutes policy initiatives}

Whether or not compromise constitutes repair, there is another important implication of Proposition 2. Any policy change of Medicare (or of the private payer) will be diluted by the provider's compromise. The provider's compromise, $q^{e}$, can be thought of as a weighted average of the profit maximizing policy for the private sector alone $q_{\mathrm{P}}^{e}$ and the Medicare-alone policy $q_{\mathrm{M}}^{e}$. This is depicted above in Fig. 1. Dilution is about the slope of the Medicare and private payer line in comparison to the Medicare only line. A change in Medicare premium affects the quality Medicare buys less in proportion to the presence of the private payer. Formally, this could be shown by taking the derivative of $q^{e}$ with respect to $r_{\mathrm{M}}$ in (3.11) and noting the increase dependence of this derivative on $N_{\mathrm{P}} / N_{\mathrm{M}}$. 
The impact of dilution also extends beyond the policy about the level of Medicare premium. Medicare contends with adverse selection by risk adjusting the premiums it pays to health plans. Risk adjustment moderates the selection problem by increasing payment amounts for observable characteristics of an enrollee, like age, that are correlated with expected health costs. The impact of a change in risk adjustment policy is also diluted. Any "improvement" in risk adjustment may have a small impact on plan behavior because of dilution.

The dilution result has several interesting empirical implications. One prediction is that the effects of changes in Medicare's policy (e.g., premium, parity) on the quality of services Medicare's enrollees receive e.g., length of a visit or hospital stay, intensity will depend on the share of Medicare's patients in the provider's total number of patients. Another prediction is that the change in the number of Medicare enrollees using a particular provider as a result in a change in Medicare's premium will also depend on the share of Medicare patients in the provider's total number of patients.

Taken together, the repair and dilution ideas throw Medicare's problem of price setting in a new light. With respect to commonly set elements of quality, if Medicare is a small payer, the repair perspective says that if the private sector is an effective contractor with providers, Medicare need not worry about how its price policy affects a provider's incentives for setting quality. The dilution idea says, even if Medicare did try to affect quality by risk adjustment or other price adjustment, it would be have little effect.

\subsection{A strategic Medicare free rides on the private sector}

To now we have studied the implication of a provider's decision about quality, and treated Medicare's price as a parameter in that decision. Certainly it is reasonable to assume that a provider takes Medicare's price policy, and the functioning of the private market, as given. In this section we address Medicare's decision about price. Medicare has the opportunity to behave strategically: to commit to a price, anticipating the private sector and providers' response to its policy. Medicare's best policy will be to set price low, and induce the private sector to partially repair this mistake. In its strategic response to compromise on quality with the private sector, Medicare can be expected to free-ride.

So long as Medicare can commit to a price, even if it is small payer, Medicare can be regarded as a leader in a leader-follower model of choosing shared quality. Define welfare for Medicare in a general way to be $S_{\mathrm{M}}\left(q, r_{\mathrm{M}}\right)$, a function of the quality chosen by the plan and the price Medicare pays. ${ }^{13}$ Both $\partial S_{M} / \partial q$ and $\partial S_{M} / \partial r_{M}$ are negative, reflecting the fact that increases in either stringency of rationing or the price decreases Medicare welfare. The schedules relating price to quality are the opportunity loci facing Medicare with different relative sizes of the private sector. In Fig. 2, we add equal-surplus lines for Medicare in $\left(q, r_{\mathrm{M}}\right)$-space. As before, the Medicare-only $q_{\mathrm{M}}\left(r_{\mathrm{M}}\right)$ line is much steeper than the Medicare and private payer line, reflecting the fact that quality responds more to Medicare price changes when Medicare is the only payer.

\footnotetext{
13 In the analysis here we abstract from other elements that may affect Medicare's welfare such as the distortion created by the financing of Medicare's services.
} 


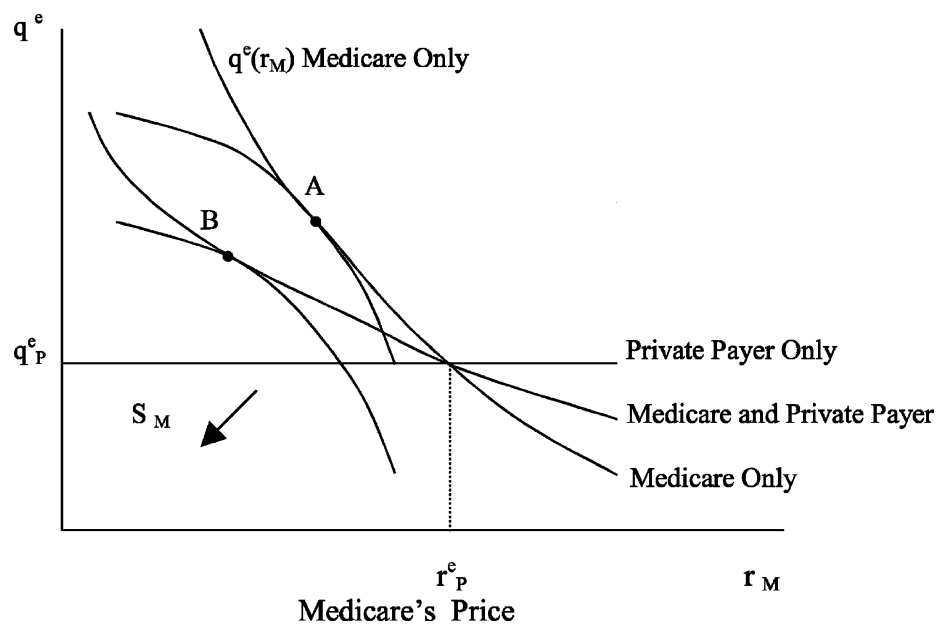

Fig. 2. Medicare's choice of price level.

Suppose Medicare would choose point A if it were the only payer, where $r_{\mathrm{M}}<r_{\mathrm{P}}^{e}$ and, hence, $q_{\mathrm{M}}^{e}>q_{\mathrm{P}}^{e}{ }^{14}$ Now, introduce the private sector. The trade-off between $q^{e}$ and $r_{\mathrm{M}}$ flattens: Medicare can reduce the price and not suffer such a large increase in stringency of rationing because of the reparative private sector. Medicare could choose point $\mathrm{B}$. With the same iso-surplus lines, when $r_{\mathrm{M}}<r_{\mathrm{P}}^{e}$, Medicare is better off by the presence of the private sector. Medicare will reduce $r_{\mathrm{M}}$ in comparison to the Medicare-only case. ${ }^{15}$ This characterization of Medicare's optimization need not be taken literally. Still, the tradeoffs presented to Medicare by a large or small private presence in a plan can help explain Medicare's choice of payment policy.

In this leader-follower model, Medicare can be said to free-ride on the private payer since its surplus $S_{\mathrm{M}}\left(q, r_{\mathrm{M}}\right)$ increases in the presence of the private payer. Medicare can exploit the private repair function by reducing its payment in response to the presence of the private sector.

Proposition 2 (Free-riding). For a given $N_{\mathrm{M}}$ and $r_{\mathrm{M}}<r_{\mathrm{P}}^{e}$, the larger is $N_{\mathrm{P}}$, the larger is Medicare's surplus, $S\left(q^{e}, r_{\mathrm{M}}\right)$.

Medicare benefits from being small and being able to buy private sector quality at a low price. Medicare has a strategic interest in promoting commonality in services with private sector.

\footnotetext{
${ }^{14}$ In this section we treat Medicare as acting so as to maximize an objective function, an assumption that can certainly be questioned. Also, Medicare must set its premium policy on a program-wide basis, not plan-by-plan. The analysis here is simply meant to characterize the incentive Medicare faces to exploit the presence of the private payer.

15 Things can work the other way. If instead of choosing an $r_{\mathrm{M}}<r_{\mathrm{P}}^{e}$, Medicare chooses $r_{\mathrm{M}}>r_{\mathrm{P}}^{e}$. Then, the flattening of the $q-r_{\mathrm{M}}$ trade-off would mean that Medicare would have to pay even higher premium to induce the same quality in the presence of the private sector. The "evidence" on the Medicare program suggests that this is not the empirically relevant range.
} 


\subsection{Plans must be compensated to accept Medicare}

One of the persistent policy issues in the Medicare program is the participation of plans and providers. Participation by health plans in Medicare's captivation payment program has never been high, and recently it has turned dismal. The number of contracting plans dropping to 148 in January 2002, from a peak of 346 several years earlier (MedPAC, 2002). ${ }^{16}$ The participation decision works out differently for hospitals and physicians. Virtually all hospitals take DRGs as payment. Rates of participation by physicians in Medicare are high.

Across all providers, participation comes down to a comparison of Medicare revenues and costs. Because some elements of quality are shared, the cost of participating with Medicare must reflect the effect of participation on the shared quality. This observation introduces a new perspective on providers' decisions, and may help explain the observed pattern of participation.

We can use our model of profit maximization to define the price level at which a provider would be willing to contract with Medicare. A provider accepts Medicare if profits serving both payers exceed the profits the provider could gain by serving the private payer only. If the provider serves only the private payer, profits are $\pi_{\mathrm{P}}(q)$, from (3.10), maximized at $q_{\mathrm{P}}^{e}$. If, instead, the provider serves both the private and the public payers, the provider makes some profit from Medicare, but must make less from the private sector, since, except when Medicare chooses a certain price level, $q^{e} \neq q_{\mathrm{P}}^{e}$.

Thus, we can say that a provider will accept Medicare if the profit in Medicare exceeds the loss the provider would bear by altering quality in the private sector. Specifically, the provider accepts Medicare if:

$$
\pi_{\mathrm{M}}\left(q^{e}\right) \geq \pi_{\mathrm{P}}\left(q_{\mathrm{P}}^{e}\right)-\pi_{\mathrm{P}}\left(q^{e}\right)
$$

Since $q^{e} \neq q_{\mathrm{P}}^{e}$, the right-hand side of (4.1) will be positive and determine the threshold profit necessary for a provider to accept Medicare. This is a formalization of our observation that even though it may always be possible for a provider to make some profit from Medicare, this profit might not be enough to induce a provider to accept Medicare. The sacrifice in profit from altering the jointly set quality could be too high. We can state this observation more formally.

Proposition 3 (Participation). For a given health provider and $N_{\mathrm{M}}$, let $\underline{r}_{\mathrm{M}}$ be the lowest Medicare price at which the provider will accept Medicare enrollees. The larger is $N_{\mathrm{P}}$ the larger is $\underline{r_{\mathrm{M}}}$.

Proof. $\underline{r}_{\mathrm{M}}$ is the price that solves the following equation:

$$
\pi_{\mathrm{M}}\left(q^{e}\left(\underline{r_{\mathrm{M}}}\right)\right)+\pi_{\mathrm{P}}\left(q^{e}\left(\underline{r_{\mathrm{M}}}\right)\right)-\pi_{\mathrm{P}}\left(q_{\mathrm{P}}^{e}\right)=0
$$

where $q^{e}\left(r_{\mathrm{M}}\right)$ is the shadow price $q^{e}$ that solves (3.11) given a Medicare premium $r_{\mathrm{M}}$.

\footnotetext{
${ }^{16}$ For discussion, see Falk (1999), Call et al. (2001), Cawley et al. (2001), and Town and Liu (2001).
} 


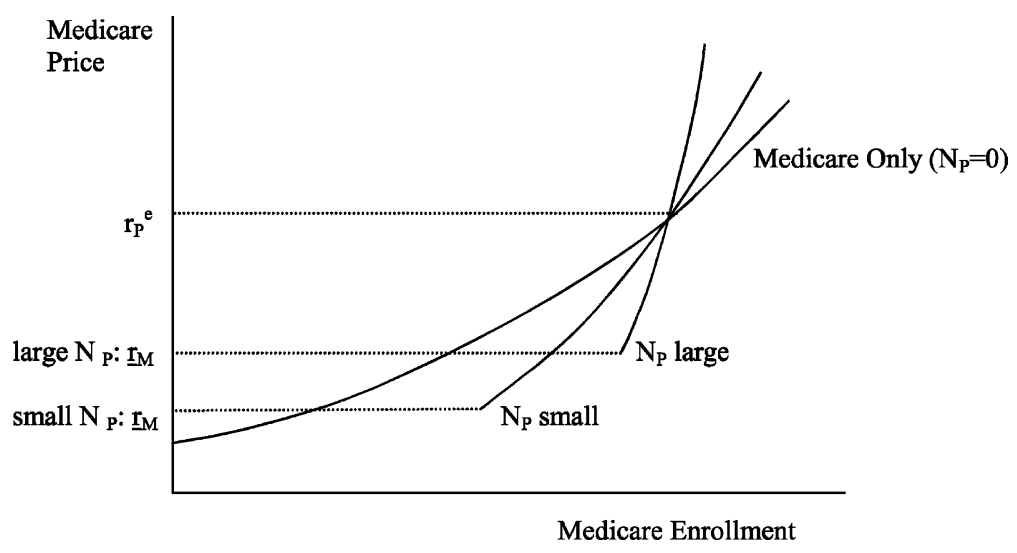

Fig. 3. Supply of Medicare enrollment at a plan.

Using (3.6), (3.8), (3.10)-(3.12) and (4.2) it can be shown that

$$
\frac{\partial r_{\mathrm{M}}}{\partial N_{\mathrm{P}}}=-\frac{N_{\mathrm{P}}\left(H\left(q^{e}\left(\underline{r_{\mathrm{M}}}\right)\right)-H\left(q_{\mathrm{P}}^{e}\right)\right)}{N_{\mathrm{M}} n_{\mathrm{M}}\left(q^{e}\left(\underline{r_{\mathrm{M}}}\right)\right)}>0
$$

Although the model applies to all providers, the currently most important question about participation is in the context of health plans. ${ }^{17}$ Plans' refusal to participate can be regarded as a puzzle: for any given Medicare premium level, why not set quality (cost) very low, and be willing to take any beneficiary who joins on those terms? If quality (cost) can be customized to Medicare beneficiaries, there should be a way to make profits for any level of Medicare payment by reducing quality low enough. Administrative costs special to Medicare are certainly part of the reason behind low participation, but this may not be the only factor at work. If some aspects of quality must be set jointly with another (larger) group of payers, the loss on the private side from adjusting to Medicare conditions might not be made up by any profits from Medicare. Widespread plan refusal to contract with Medicare is consistent with the key assumption of this paper that plans must set some policies jointly for multiple payers.

The relationship between Medicare premium and health plan participation and entry implied by (4.2) is shown in Fig. 3. The "Medicare-only" supply curve shows, for one plan, the premium necessary to induce entry at all, and the enrollment as a function of $r_{\mathrm{M}}$. This line is relatively elastic because when Medicare is the only payer, the $q$ chosen by the plan is responsive to the Medicare premium (Fig. 1). The participation proposition implies that as $N_{\mathrm{P}}$ goes up, $\underline{r_{\mathrm{M}}}$ goes up. We show $\underline{r_{\mathrm{M}}}$ for a small and large $N_{\mathrm{P}}$. Dilution implies that given that the plan accepts Medicare, the response of $q$ (and enrollment), will be less as $N_{\mathrm{P}}$ rises. We have drawn the two new supply curves in Fig. 3 to reflect the dilution.

\footnotetext{
17 DRG payments are based on historical average cost. When there is widespread excess capacity in the industry, short run variable hospital costs will be below DRG payments, and all hospitals will participate. As hospital capacity adjusts to demand, hospital participation into Medicare could become an issue.
} 
Hypotheses about the structure of markets and entry implied by the participation proposition could be subject to empirical tests. Some recent papers examine which plans accept Medicare enrollment from which counties, but the factors determining plan decisions are limited to cost and revenue from Medicare alone (the left hand side of (4.1)). ${ }^{18}$ Our analysis suggests that additional considerations from the private sector would also matter. For example, if the private market were very competitive, the loss in profit from the private sector would be less of a consideration than if the market structure left more of the surplus with the plan. Plan participation with Medicare is both low and falling. Commonality has to do with the low part of this statement, not the falling part. There is no reason to think that factors related to shared quality have changed recently, so other factors associated with Medicare payment reforms are more likely to explain the recent plan flight from Medicare.

\section{Conclusions}

Our analysis of commonality has implications for Medicare's payment policy. With respect to elements of shared quality, in markets where Medicare is a small payer, the details of its administrative rules and price formula are not important to incentives of the provider. For example, Medicare may be focusing too much on the details of its health plan payment formulae with little effect on the quality of services offered by plans. If private payers practice reasonably efficient contracting, Medicare mistakes will be repaired, and in any case, Medicare initiatives will be diluted. Medicare's main problem in the health plan market is lack of plan participation, the precipitous fall in rates in the past few years suggesting that a fresh approach is called for. Simply raising rates would increase enrollment but it is expensive to get more beneficiaries in captivated plans by raising national rates. When quality is shared, once a plan participates with Medicare, enrollment responds little to increases in payment rates because they have a diluted effect on plan characteristics. Moving to plan-specific prices, like the private sector, and like the federal government when it buys for its employees, may be advisable for Medicare too.

In broader terms, we believe more attention should be paid to the consequences of Medicare and private purchasers, with their distinctive purchases practices, buying from the same plans and providers. A notable result of our analysis is that by committing to a price, Medicare can free-ride on the private sector. If private contracting is reasonably efficient, succumbing to the temptation to free-ride will reduce shared quality below the efficient level for all payers. In this case, pursuit of narrow Medicare program objectives conflicts with social efficiency. As we noted above, however, the judgment on Medicare would turn out differently if Medicare's use of its position as a leader in the payment game were putting the brakes on a health care system pushed to excess by tax subsidies to private employers. Interacting purchasing strategies of the multiple payers in health care, and the response of providers to these strategies, are salient to analysis of US health policy. Although the analysis is this paper was specific to Medicare/private interactions within a US policy context, shared quality by providers in settings outside the US will raise similar issues.

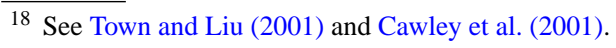


Empirical research could be directed to measuring the importance of shared quality for plans, hospitals and physicians. While the presence of multiple payers from providers and health plans is self-evident, the degree of commonality in shared quality is not. One interesting question is the degree of commonality in the provider networks health plan assemble for their Medicare and private "products." Empirical research can check, along the lines of Glied and Zivin (2002), if "practice-level" incentives matter along with "payer-level" incentives in the behavior of providers, in order to check for commonality. In the course of the paper, we have noted some empirical implications for study of Medicare policies. The dilution idea implies testing an "interaction term" of Medicare policy change with share of Medicare at a provider or plan.This test has potentially wide empirical application.

\section{Acknowledgements}

This paper was presented at the Fifth Biennial Conference on the Industrial Organization of Health Care, 23-25 September 2001. We thank Zhun Cao, Randy Ellis, Elaine Fleming, Hsienming Lien, Sharon-Lise Normand, Richard Frank, Albert Ma, David Mandy, Joe Newhouse and Alan Zaslavsky for helpful comments on earlier drafts. We are grateful to the Management Sciences Group of the Veterans' Administration, the Agency for Health Care Research and Quality (P01 HS10803), the National Institute of Mental Health (R01 MH59254) and the Institute for Business Research in Israel for support for this research.

\section{References}

Beaulieu, N., 2000. Externalities in Overlapping Supplier Networks. Harvard University, unpublished, November. Bernard, D., 2000. Do Medicare's Hospital Payments Subsidize Managed Care Plan's Costs? Agency for Healthcare Research and Quality, unpublished.

Bernheim, B.D., Whinston, M.D., 1986. Common agency. Econometrica 54 (4), 923-942.

Call, K.T., Dowd, B.E., Feldman, R., Lurie, N., McBean, M.A., Maciejewski, M., 2001. Disenrollment from Medicare HMOs. The American Journal of Managed Care 7 (1), 37-51.

Cawley, J., Chernew, M., McLaughlin, C., 2001. HMO Participation in Medicare Managed Care, Working Paper. University of Michigan.

Chalkley, M., Malcomson, J., 2000. Government purchasing of health services. In: Culyer, A.J., Newhouse, J.P. (Eds.), Handbook of Health Economics. North-Holland, Amsterdam.

Cutler, D., Zeckhauser, R., 2000. The anatomy of health insurance. In: Culyer, A., Newhouse, J. (Eds.), Handbook of Health Economics. North-Holland, Amsterdam.

Encinosa, W.E., Sappington, D.E.M., 1999. Adjusted community rate reforms to private HMO participation in Medicare+choice. Health Care Financing Review, Fall (21:1), 19-29.

Falk, S., 1999. Medicare managed care plans plot further exits from certain markets. Managed Care Reporter $(5,20), 474$.

Feldman, R., Dowd, B., 2000. Risk segmentation: goal or problem? Journal of Health Economics 19, 499-512.

Frank, R., Glazer, J., McGuire, T., 2000. Measuring distortions from adverse selection in managed health care. Journal of Health Economics (19:6), 829-854.

Gertler, P.J., 1989. Subsidies, quality, and the regulation of nursing homes. Journal of Public Economics 38 (1), $33-52$.

Glazer, J., McGuire, T.G., 2002. Setting health plan premiums to ensure efficient quality in health care: minimum variance optimal risk adjustment. Journal of Public Economics 84, 153-173.

Glied, S., Zivin, J.G., 2002. How do doctors behave when some (but not all) of their patients are in managed care? Journal of Health Economics 21 (2), 337-354. 
Goldstein, G.S., Pauly, M.V., 1976. Health insurance as a local public good. In: Rosett, R. (Ed.), The Role of Health Insurance in the Health Service Sector. National Bureau of Economic Research, New York, pp. 93-110.

Grabowski, D.C., 2001. Medicaid reimbursement and the quality of nursing home care. Journal of Health Economics 20 (4), 549-569.

Holahan, J., Rangarajan, S., Shirmer, M., 1999. Medicaid managed care payment methods and captivation rates: research of a national survey, Occasional Paper Number 26. The Urban Institute, Washington, DC.

Interstudy, 1999. The 9.1 HMO industry report press release: total HMO enrollment continues to increase. Growth Rates Slow Significantly, 10 May 1999.

Katz, M.L., 1989. Vertical contractual relations. In: Schmalensee, R., Willig, R. (Eds.), Handbook of Industrial Organization, pp. 655-722.

Keeler, E., Newhouse, J., Carter, G., 1998. A model of the impact of reimbursement schemes health plan choice. Journal of Health Economics 17 (3), 297-320.

Keenan, P., Beeuwkes-Buntin, M., McGuire, T., Newhouse, J., 2001. The prevalence of risk adjustment. Inquiry (38:3), 245-259.

Ma, C.-T.A., 1994. Health care payment systems: cost and quality incentives. Journal of Economics and Management Strategy (3,1), 93-112.

Ma, C.-T.A., McGuire, T.G., 1993. Paying for joint costs in health care. Journal of Economics and Management Strategy 2 (1), 71-95.

Marquis, M.S., Long, S., 1999. Trends in managed care and managed competition. Health Affairs 18 (6), $75-88$.

McGuire, T.G., Pauly, M.V., 1991. Physician responses to fee changes with multiple payers. Journal of Health Economics 10 (4), 385-410.

McNeil, B.J., 2001. Hidden barriers to improvement in the quality of care. The New England Journal of Medicine 22 (345), 1612-1620.

Medicare Payment Advisory Commission, 2002. Report to the Congress: Medicare Payment Policy. Author, Washington, DC, March 2002.

Merck, C.L. The Federal Employees Health Benefits Program. Congressional Research Service, 12 October 1999.

Newhouse, J., 2002. Pricing the Priceless: A Health Care Conundrum. MIT Press, Cambridge.

Pope, G.C., Ellis R.P., Ash A.S., et al., 2000. Principal inpatient diagnostic cost group model for Medicare risk adjustment. Health Care Financing Review, Spring (21,3), 93-118.

Town, R., Liu, S., 2001. The Welfare Impact of Medicare HMOs, Working Paper. University of California-Irvine. Scanlon, W.J., 1980. A theory of nursing home market. Inquiry 17, 25-41.

van de Ven, W.P.M.M., Ellis, R.P., 2000. Risk adjustment in competitive health plan markets. In: Culyer, A.J., Newhouse, J.P. (Eds.), Handbook of Health Economics. North-Holland, Amsterdam.

Yip, W., 1998. Physician response to Medicare fee reductions: changes in the volume and intensity of supply of coronary artery bypass graft (CABG) surgeries in the Medicare and private sectors. Journal of Health Economics $17,675-700$. 